DOI: 10.14526/2070-4798-2019-14-3-23-25

\title{
Physical plasticity as the quality, which increases the level of dancers' technical mastery
}

\author{
Svetlana P. Klemenchuk* \\ Stavropol State Pedagogical Institute \\ Stavropol, Russia \\ ORCID: oooo-ooo2-4438-2798, svetipulik@mail.ru*
}

\begin{abstract}
Choreographic art quickly develops in modern world. There appear new directions and techniques, which demand dancers' special training. There are a lot of methodologies. They provide technical mastery development. However, expression formation doesn't have the definite algorithm of development. Materials. Modern methodologies analysis of technical skills formation. Research methods. Scientific sources analysis and summarizing. Results. Modern methodologies analysis and synthesis helped the author to reveal the most effective way of technical mastery development by means of physical plasticity development. Conclusion. Physical plasticity will help to form dancers' expression of movements, their performing and spectacular semiotics. Dancing differs from other forms of art not only because its object is a human body, but also owing to the fact that in dancing masterpiece appears before the eyes of people.
\end{abstract}

Keywords: choreographic art, technical mastery, expression, technique, dancer, physical plasticity.

For citation: Svetlana P. Klemenchuk*. Physical plasticity as the quality, which increases the level of dancers' technical mastery. Russian Journal of Physical Education and Sport. 2019; 14(3): 23-25. DOI: 10.14526/2070-4798-2019-14-3-23-25

\section{INTRODUCTION}

Nowadays chorographic art is popular all over the world. It is characterized by a high level of difficulty, originality and dynamism of movements. Each direction has its own specific elements, the performance of which demands gaining new technical skills.

\section{MATERIALS AND METHODS}

There are different methodologies of technical mastery formation: classical dancing methodology (A.Y. Vaganova), the technique of male technical mastery(N.I.Tarasov), folkstage dance methodology (G.P. Gusev), improvisation in dance (Ted Shawn), direction of working with the body, connected with body and consciousness centrality (B. Cohen) and others.

In his works Litvinenko S.N. states that all mentioned above methodologies are based on body oriented approach. The main aim of this approach is to form motor qualities [4, p. 26].

Dancers' motor qualities achieved a new level of the definite set of physical qualities. Earlier such qualities were formed with the help of a classical training simulator, however today in groups for children different elements of acrobatics and gymnastics are actively used. These elements increase flexibility $[1, \mathrm{p} .20]$.

\section{RESULTS AND DISSCUSION}

However, in theory the effect of going in for choreography is connected with the fact that during the process of specially organized tiredness we activate rehabilitation processes and it helps to achieve great success in physical peculiarities of an organism formation. Stage dance technique becomes more complicated. Sometimes dancers try to attain showiness, sports excitement of dancing elements fulfillment. However, they don't pay much attention to cantilence (melody), musicality and spirituality of plasticity-all these elements are the features of the Russian school of dance. Teachers think that the main aim is to provide students with masterly technique, which is usually done in prejudice of artistry and expressiveness development. As a result, "choreographic text stops being the language which dancers "speak" [9, p. 14]. Modern teachers in choreography more often try to pay attention to the problem of preserving the traditions of bringing up dancing expression. It is important for technical skills formation, as it has considerable drawbacks (a dancer's personal interests and needs are ignored).

Dance is summarized and polysemantic. Dance abstracts, gives practical answers to theoretical questions concerning itself, environment, a person's life meaning. Dance is able to express every detail of a person's state. It provides self-realization, helps to confide to the world. However, very often we hear aggressive music, which is based on dissonances or we hear too sweet and arch-sweet music. Very often the texts of the songs are created by degenerating fashion or political system, which is also popular 
nowadays. The truth is hidden. The truth is that dance is dead. Now it is just a poor excuse for a dance, which only tries to satisfy the public (if we don't mean highly-professional stage dance, but a harmonious dance of the soul and the body).

Nowadays we can state that a dancer achieves success if his "aesthetic" component of technical mastery predominates.

I.M. Sechenov was the first scientist, who revealed the dependence of a person's body movement on his psychic state. Iatromechanics (predecessor of biomechanics) is based on this idea and opens psychic determinism. This principle helps to study casual relations, which study movements with the help of natural scientific apparatus and shows that the sphere of a human psyche reflects the reason of a free motor act. A psychic state activates (determines) a movement and is revealed in motor actions. This phenomenon understanding correlates with the research works by N.A. Bernshtein. Studying physical qualities of a person, he revealed that together with the view of mechanical thinking such physical qualities as power, quickness, dexterity, endurance combine not only physical, but also psychic [3, p. 33].

N.A. Bernshtein was the first scientists, who "returned soul to the movement" and who substantiated the principle of psychic determinism in terms of physical culture theory. As a person's movements were the object for mathematical description, he started to study movements in order to understand how they are produced and controlled. He opens a new sphere of a scientific cognition "physiology of activity". This scientific sphere is based on a new understanding of movement, motor action determination and a person's life in general.

It should be noted that "body experience" phenomenon gives reasons for body movement (and physical culture) inclusion into the sphere of civilizational culture. This phenomenon transfers an individual into a personality. A motor action through the prism of a body experience is not only reasonable, but also value conformable and culture conformable [3, p.34].

It is obvious that in a technical mastery, apart from technique itself, it is necessary to form both expression and body plasticity. It is an important skill in choreography. Emotionality, image in choreography always provided its popularity and development, in contrast to other kinds of physical upbringing.

As a person accumulates a lot of emotions during his life, it is necessary to define the principles of educational task modeling, which determine the following: body-motional, plastic, metrorhythmic and spatio-orientation structure of a movement, its methodical orientation and the most important its aesthetic image.
Moreover, each student should know that apart from the obligatory technique principles fulfillment in a dancing combination, it is necessary to realize several artistic-creative objectives, added by the following tasks oriented towards dancing expression upbringing. For example, notional logic of movements realization, given by the teacher (a movement gains expressive notional content which has the meaning for the performer). Taking into account individual peculiarities of each person, a teacher should discuss with the dancer his association concerning the stated task. If it has symbolic or abstract meaning, it is necessary to define its content, which is perceived and reproduced by students.

As S. Filatov mentions, in order to form the definite emotional-figurative mode- a mindset, which provides special emotional-psychic state for students, educational combinations should be full of plastic emotions or the definite figurative character, mood, feeling transferred through the plastic art, mimicry and a dancing gesture, without the canons of a classic dance violation. That is why figurative comparison is the main and effective means. It is used by a teacher in the methodology of a movement fulfillment. It helps to perceive, experience and fulfill it in accordance with motor objectives. Figurative, artistic word helps a teacherchoreographer not only to reveal the content of a musical image, but also creates the definite mood of a dancer, increases his interest and motivation to fulfill a movement. "Very often in class we can hear how a teacher characterizes a movement, helping to fulfill a combination with expression and achieve technical accuracy" [2, p. 80]. "Flying gestures" this way M.Taloni, L.D. Blok characterized hands.

In "Classical dance school" Kostrovitskaya V.S., Pisarev A.A. mentioned the following: "In the 3rd position the movement is started from the hands, they open like flower petals" (at the same time arms don't start a movement sideward, they rise with the hands during the first moment of their movement upwards). In battement tendu Nikolai Ivanovich Tarasov demanded "a juicy foot", "full" muscles and "a sense of length" in a leg starting from the hip till the toes, the sense of "a bar", "stately body" [8, p. 9]. It means that a motor action based on a body plasticity provides imagination development and perception peculiarities formation, both cerebral hemispheres activation. Taking into consideration psychic regularities of excitation and inhibition processes psychologists and teachers underline, that attention focusing on the mechanisms of movement fulfillment distracts a person's mind from life problems, from external stimuli, as a person's image thinking, regardless of age includes three thinking processes: image creation, image operating and orientation in space. All three processes have one 
base and influence cognitive "image thinking" sphere regardless of activity kind and content. It means that during choreography lessons dancers should contact the sphere of image metaphorical cognition (E. Cassirer calls it "metaphorical thinking"). The problem of mastering metaphorical means is traditionally solved in terms of verbal and aesthetic upbringing, as metaphor is a general means of original worldview provision and deep spheres of human culture mastering $[8,9,10,11,12]$.

Thus, modern methodologies of technical skills formation should combine technical level of physical qualities development in dancing. It is determined according to "technical" orientation methodologies, characterized by steadiness, completeness, legs power, endurance, movements smoothness indices improvement and etc. and fulfillment expression: gestures, mimicry, meaning realization during movements fulfillment and information transfer to the audience. Modern methodology, which increases the level of technical mastery, includes the following methods:

- the choreographer's explanation and studying general scheme of figures connection by a dancer (movement in general);

- figures connection recurrence (the separate figures) till they are perfectly fulfilled;

- while mastering the mentioned material mistakes correction in the whole connective and its recurrence;

- a teacher tells about choreographic image (notion) of the set movement;

- the received information about the movement analysis and synthesis by a dancer, mastering expression means, which provide information transfer [6, p. 86].

Physical plasticity will help to form dancers' expression of movements, their performing and spectacular semiotics. Dancing differs from other forms of art not only because its object is a human body, but also owing to the fact that in dancing masterpiece appears before the eyes of people.

\section{REFERENCES}

1. Borisenko S.I. Technical mastery improvement among female gymnasts on the basis of choreography improvement. Moscow, 2018: 160.

2. Karpenko V.N., Karpenko I.A., Filchakova E.A. Dance as a soul revelation. Tambov: Gramota.
2015; 5 (55); 2: 66-69.

3. Klemenchuk S. P. Physical plasticity of movements formation among female teen-agers: Candidte's thesis. Maykop, 2016;260.

4. Martynova M. A. Contact improvisation in the context of psychological practice. Aktualnye voprosy sovremennoi psikhologii: materialy II-oj Mezhdunarodnoj nauchno-prakticheskoj konferencii (Chelyabinsk, Fevral' 2013) [Topical issues of modern psychology: materials of the II International scientific-practical conference (Chelyabinsk, February, 2013)]. Chelyabinsk:Two cosmonauts. 2013: 22-25 (In Russ.)

5. Terekhina R.N., Borisenko S.I. Technical mastery improvement among dancers. Uchenye zapiski universiteta imeni P.F. Lesgafta [Scientific notes P.F. Lesgaft University]. 2006; 20: 80-84

6. Kuramshin Y.F. Theory and methodology of dancing culture. Moscow: Soviet sport. 2003: 480.

7. Baldari C., Guidetti L. VO2max, ventilator and anaerobic thresholds in rhythmic gymansts and young female dancers. Journal of Sports Medicine and Physical Fitness. 2001; 41(2): 177-182.

8. Guidetti L., Gallotta M.C., Emerenziani G.P., Baldari C. Exercise intensities during a ballet lesson in female adolescents with different technical ability. International journal of Sports Medicine. 2007; 28(9): 736-742. DOI: 10.1055/s-2007964909.

9. Koutedakis Y., Jamurtas A. The dancer as a performing athlete: Physiological considerations. Sports Medicine. 2004; 34(10): 651-661. DOI: 10.2165/00007256-200434 100-00003.

10. Wyon M.A., Abt G., Redding E., Head A., Sharp N.C. Oxygen uptake during modern dance class, rehearsal, and performance. Journal of Strength and Conditioning Research. 2004; 18(3): 646-649.

11. Wyon M.A., Redding E. Physiological monitoring of cardiorespiratory adaptations during rehearsal and performance of contemporary dance. Journal of Strength and Conditioning Research. 2005; 19(3): 611-614.

12. Aleksandr S. Kuznetsov. Russian Professor's meeting. Pedagogiko-psihologicheskie I medicobiologicheskie problemy fizicheskoj kul'tury I sporta $=$ The Russian Journal of Physical Education and Sport. 2019; 14(1): 17-22. DOI: 10.14526/20704798-2019-14-1-18-24. (In Russ., In Engl.)

\section{Submitted: 20.08.2019}

Author's information:

Svetlana P. Klemenchuk - Candidate of Pedagogical Sciences, Stavropol State Pedagogical Institute, 355005, Russia, Stavropol, Shpakovskaya str., House 30, e-mail: svetipulik@mail.ru. 